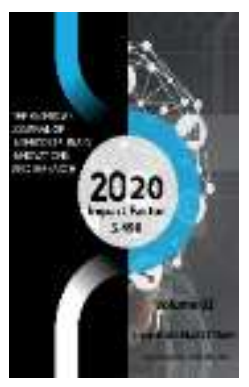

\title{
Problems And Errors Of Video Editing Beginners
}

\author{
Rustam Ergashalievich Talabbaev \\ Lecturer, Department Of Sound Directing And Cinematography,Uzbek State Institute Of Arts \\ And Culture, Uzbekistan
}

Journal Website: http://usajournalshub.c om/index,php/tajiir

Copyright: Original content from this work may be used under the terms of the creative commons attributes 4.0 licence.

\section{ABSTRACT}

This article is a huge problem for the sound director - it is about non-linear video editing. It also discusses the types and methods of teaching nonlinear editing. Therefore, this article will help users who have the necessary information about the non-linear video editing audio process.

\section{KEYWORDS}

Non-linear editing, small frames, video editor, hard disk, sound, intuitive, subconscious.

\section{INTRODUCTION}

The President of the Republic of Uzbekistan signed a decree and an ordinance (09/10/2019) aimed at creating a unified and effective system for working with gifted youth, supporting their initiative to realize talent and potential. Also, this decree says the attraction of qualified and experienced pedagogues with deep knowledge, modern pedagogical technologies and innovative teaching methods. Therefore, the author decided to write a number of articles to guide young people on the right path when editing video production.

What does "non-linear" mean, why use unknown terms right off the bat? Don't worry, we'll figure it out now. If in the case of photography we simply do not print defective pictures, deleting them from the camera's 
memory, then you simply cannot get rid of a marriage in video filming. Conclusion: Editing is not only necessary, but necessary. Trust me, no one, not even you - will enjoy counting the flickering steps later.

Don't be intimidated by the following numbers: amateur practice shows that an interesting film turns out to be only $10-20 \%$ of all filmed and captured video. That is, prepare in advance that your shooting is $90 \%$ uninteresting shots. This, of course, is about everyday life filmed with a video camera: everyday life, walks, Family holidays in general, all everyday prose. If you captured the presentation of the Nobel Prize to your son or your first flight into space these footage are priceless and cannot be edited.

\section{MAIN PART}

This material is recommended for reading for those users who have little idea of the process of nonlinear video editing (and even more so does not see the need for any editing at all). What does "non-linear" mean, why use unknown terms right off the bat? Don't worry, we'll figure it out now. If in the case of photography we simply do not print defective pictures, deleting them from the camera's memory, then you simply cannot get rid of a marriage in video filming. Conclusion: editing is not only necessary, it must be. Believe me, no one - not even you - will have the pleasure of counting the steps flickering in the frame afterwards. Don't be intimidated by the following numbers: amateur practice shows that an interesting film turns out to be only 10$20 \%$ of all filmed and captured video. That is, prepare in advance that your shooting is 90\% uninteresting shots. This, of course, is about everyday life filmed with a video camera: everyday life, walks, Family holidays in general, all everyday prose.

If you captured the presentation of the Nobel Prize to your son or your first flight into space these footage are priceless and cannot be edited. In contrast to simple (linear) editing, when video is rewritten directly from the source, nonlinear themes are remarkable for the fact that the work is carried out with the material already available on the computer's hard disk. Thus, you can work slowly, it is always allowed to return to one or another plot, correct it or even edit it again. For those who have absolutely no idea of the processes taking place during editing, it will be easier to understand and "feel" them with the help of comparisons, identifications with already familiar objects. For example, let's take a scene with the baptism of a child the duration of the clip is 60 minutes.

The main task of the editor is to cut out unnecessary parts (episodes, scenes) from this shooting, leaving only the most valuable frames. What exactly is considered interesting and uninteresting is up to you; intuition and common sense are the faithful helpers of the master. Bearing in mind the above figures, but taking into account the originality of the plot (after all, the sacrament of baptism is not an everyday event), we expect to remove about $60 \%$ of the excess video, therefore, the result of the work will be a clip of no more than 15-20 minutes. Please note: the program does not work directly with the video clip imported into it. The video editor just remembers your actions, and records them in the form of a sequence that is understandable for this program. This sequence of actions is called a project, each video editor creates its own, unique type of project (although it happens that some programs can import and work with projects created in other video editors).

For example, processing a clip named 01.avi you cut it at the 5 th second and removed the beginning. The program will remember this action and write down the information that the first five seconds of the 01.avi clip should be excluded from the project. After finishing work, the program will not make changes to the imported video file - this is impossible, 
because this clip is used as a basis. The program will create a new video file, guided by the same recorded sequence of actions, as well as based on temporary files (these temporary files are created by the program automatically in a predefined folder on your PC hard drive).

That is why any editor must ensure that there is sufficient free space on hard drives. Simple calculation: one hour of video captured from a mini DV camera is involved in the project being created - this is already 13 gigabytes. To save the result, create a new video file, the program will need about the same amount of space as for the source material (in the case of outputting a movie in different formats, this volume may vary). If you want to carry out complex editing with the imposition of various effects, transitions, titles on all videos; if you do not want to remove a minute from the original video and leave the hour-long duration of the project unchanged, then you will need another 26 gigabytes of free hard disk space (13 - for placing service information and intermediate rendering, and another 13 - for outputting the finished film).

Let's mentally break down the entire shooting into the main stages: here a mother with a child in her arms goes to the temple. Next - a meeting with her best friend, who volunteered to play the role of godmother. And, finally, the ceremony itself - more precisely, what was removed on the sly (in the temple where the action took place, for some reason it is forbidden to shoot). Now all that remains is to remove unnecessary, low-expressive frames from each scene, leaving only bright, memorable ones - those that would be well suited for photography.

Thus, we have reduced the duration of the clip by several times, without losing anything essential. Do not worry about the lost video: firstly, the original recording stored on the cassette remains with you forever. Well, secondly, imagine that instead of a video camera, you took a camera with you. How many photos could you take and then print? Fifteen or twenty, no more, well, how long will it take to view all these photos - five minutes? You see, we also win. Okay, we've decided on the cut. How do you connect the resulting scenes now?

The connection of scenes in editing is called simple: transition (in editing programs, the term Transition is used). The most common method used is the butt joint. Think of feature films - they focus on the plot, but not on the colorful transitions from scene to scene. Many editing programs (especially for amateur ones) offer many ways to stitch scenes, from dissolving to complex three-dimensional transitions. You should not get carried away by glare, flashes or flying debris; try to focus the viewer on the plot of the film.

Perhaps the most discreet transition is mixing (overlay, dissolution). There are a bunch of dissolve options, but the most commonly used one is simply changing the transparency of the overlay clip. The fact is that before creating a transition between clips, the user must make sure that these clips are "trimmed", that is, they have "spare" (invisible) information at the aligned ends. Here we see that the transition, called Cross Dissolve (cross dissolve), is located exactly in the center of the junction of two different video clips: 0o.avi and 01.avi. So what's the catch? And the fact is that the correct operation of any transition is possible only if the clips glued by this transition have the same "spare" frames: Thus, the first clip should have several spare frames after the seam, and the second - several frames before the seam. If the clips being aligned do not have such spare frames, then the created transition will be a sad picture - two mutually dissolving static frames (the last frame of the first clip and the first frame of the second clip). In this case, the installation program will give the user a signal about a malfunction (if this is included in its capabilities). For example, Adobe Premiere 
Pro shades a transition if both clips are not trimmed.

Of course, the audio belonging to the video clips is also mixed when the transition is created. Mixing can take place both automatically and manually (depending on the capabilities of the program). Usually in video editors, the simplest way of such mixing is used: the audio level of the first clip is gradually reduced (fade out) while the level of the second, on the contrary, increases (fade in). As a result, we have an almost unchanged overall sound level with a smooth transition from the first to the second. It's good that we started talking about sound. After all, he is the most important component of a film, and not only an amateur one. Unfortunately, even here technical and software tools alone are not enough: you need imagination and taste. Ideally, the music should sound constantly, throughout the entire film, only at times muffling so that the viewer pays attention and tries to hear someone's important words (it is desirable that such pauses last no more than half a minute, otherwise the viewer will lose interest in what is happening).

\section{CONCLUSION}

Here is one example of an amateur film decoding, when a well-chosen music is a single whole with a video sequence, and a pause between compositions accentuates and emphasizes the sonorous silence of the southern night after a day's storm: It seems that we have revealed the basic concepts of editing, now you can start working. But first, keep in mind: installation, even a simple one, takes a lot of time. After all, even a Hollywood film has been filmed for a year, and another one and a half is edited (and this with that army of editors and sound technicians!). Try to get used to the following formula: one minute of edited video equals one hour of work. And that is only if the editor knows how to talk to his program in "you".
The finished film can be viewed regardless of anyone's opinion. It can become the material of scientific research, measured, "translucent", correlated with other films. Complex patterns of artistic creativity can also be found in it, including the proportions of the golden ratio, which the director did not think about, but which he intuitively followed in the process of a long work on the film.

We have not analyzed either the inner monologue, or the editing movement of the camera, or the transformation of time, or proportionality in the construction of the plot. Widescreen, color and stereoscopic films have changed the nature of screen perception, new possibilities and nuances of editing interpretation have appeared. All this could not fit into the limited volume of one article. The author hopes to consider these problems in the following articles.

\section{REFERENCES}

1. Decree of the President of Uzbekistan dated 09/10/2019 on work with youth.

2. Sergey Merkov. Video editing for beginners.

3. Felonov L.B. Problems and trends of modern installation 